\title{
Designing a lab course from the perspective of the flow theory
}

\author{
Anna Karelina \\ California State University, East Bay, 25800 Carlos Bee Blvd, Hayward, CA 94542, USA \\ Diablo Valley College, 321 Golf Club Rd, Pleasant Hill, CA 94523, USA
}

\begin{abstract}
Students' frustration could be a crucial factor preventing successful implementation of inquiry-based learning environments. Here we describe the results of improving students' attitudes towards open-ended ISLE labs where students design their own experiments. We apply the "flow" framework to analyze students' responses to the survey concerning their experience during the labs. We describe the revisions of the course based on this analysis that resulted in a significant improvement of students' attitude toward the labs.
\end{abstract}

Keywords: inquiry-based labs, student responses, flow theory. PACS: $01.50 . \mathrm{Qb}, 01.40 . \mathrm{Fk}$

\section{INTRODUCTION}

Recently physics education research has demonstrated effectiveness of inquiry-based physics laboratories that help students acquire experimental skills. For example, labs developed within Investigative Science Learning (ISLE) system help students develop abilities to plan an experiment, test a hypothesis, analyze data, evaluate uncertainties and assumptions, and communicate their ideas [1].

However, implementation of such labs can be challenging both for the students and the instructors. Many researchers report that students sometimes exhibit negative attitudes towards inquiry-based laboratories, and sometimes such labs have lower student evaluations compared to traditional labs. Students admit effectiveness of the approach but it is mixed with frustration and poor self-evaluation $[2,3]$. In this paper we investigate students' evaluations of the lab course and their responses to an attitude survey. We apply the theoretical framework of "flow" [4] to analyze students' responses and to adjust the laboratory course accordingly. We show that the flow framework is a powerful tool for understanding students' difficulties and improving their attitudes.

\section{FLOW THEORY}

The theory of flow as a psychological experience was proposed by Csikszentmihalyi [4] to describe the experiences of people fully engaged in an activity chosen for its own sake, called an experience of flow. Nakamura and Csikszentmihalyi [5] identified the factors encompassing flow: focused concentration on the present moment; merging of action and awareness; a loss of reflective self-consciousness; a sense of personal control; a distortion of temporal experience, one's subjective experience of time is altered; and experience of the activity as intrinsically rewarding. Flow theory describes several conditions that have to be met to achieve flow state: a) knowing what to do; b) knowing how to do it: c) knowing how well you are doing; d) high perceived challenges; e) high perceived skills; f) freedom from distractions.

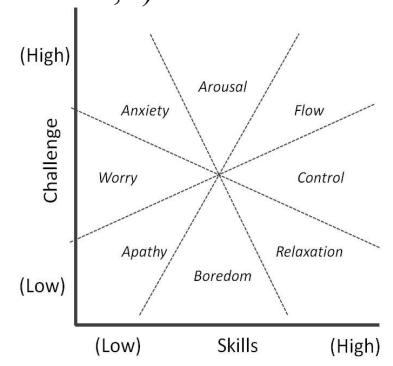

FIG. 1. Mental state in terms of challenge level and skill level, according to the eight-channel model of flow. Adapted from Ref. 6.

The further developments of theory resulted in the eight-channel model of flow, depicting the channels of experience that result from different levels of perceived challenges and perceived skills (see Figure 1) [6]. In this model flow occurs when both perceived challenge and skills are high. Other combinations results in states such as control, relaxation, boredom, apathy, worry, anxiety, and arousal.

The most effective learning happens in states of arousal and flow when the difficulty level is slightly above the skill's level. Thus if we want students learn effectively and enjoy the learning process we have to focus on creating conditions for these mental states.

Traditional methods to detect and measure the state of flow and other mental states involve experience sampling method or flow questionnaire [7]. Both require filling rather lengthy and frequent surveys difficult to administer in a regular lab setting.

\section{DESCRIPTION OF STUDY}

The study was conducted in a small liberal arts college in the southwestern United States. The 
project involved development of a lab component of a four-semester sequence of introductory calculusbased physics courses for physics and engineering majors.

There were three 55-minutes lectures and one 3-hour lab per week in the course. The physics department found that traditional labs were extremely ineffective in preparing students for future work. The department made a decision to revise the lab course adapting ISLE labs approach. The basic philosophy of these labs was for the students to learn physics through the processes of scientific investigation. Rather than illustrating established physics concepts through prepackaged demonstrations, students had to design their own experiments to observe a new phenomenon, propose a hypothesis and test it or apply a tested theory for solving a practical problem [8].

The first semester was "Waves and Optics". The second spring semester was "Mechanics". Here we will focus only on the second semester.

The first implementation of newly developed Mechanics lab course was in the spring of 2012. There were 35 students in the course. Most of these students took the "Waves and Optics" course before and were exposed to the ISLE labs structure.

At the end of each semester, we assessed the students' attitude towards the course with a survey consisting of 10 Likert scale-type questions and 5 openended questions. After we analyzed the results of the first assessment in the summer of 2012 we revised the lab course based on this analysis. In the spring of 2013, we implemented the revised version of the Mechanics lab course. In this paper we focus on students' responses to two open-ended questions: "Which lab did you like the most? Explain" and "Which lab did you like the least? Explain" and two Likert scale questions on the scale from 1 to 7: "To what extent was the instructor's assistance needed?" and "To what extent were these labs fun and interesting".

Spring 2012, First year observations The learning outcomes of the first implementation of the labs were quite encouraging [9], but in the survey students' attitude toward labs was not favorable. Students considered writing reports to be boring and annoying: 'I just don't think there should be a report for each one[lab]. I think if there were no lab reports I might like physics more." Many students did not feel comfortable doing error analysis. They expressed it in their responses to survey: "[I] still don't entirely understand uncertainties; maybe go over in class because they are new material and very important," demonstrating high-perceived challenges and lowperceived skills.

The survey questions about the most and least liked labs allowed us to identify the students' attitudes to the most memorable labs. That gave us a clue for finding labs' features that match or mismatch the flow conditions.

The most favorable lab in this class was "Measurement of $g$ " [10]. One of the methods (Fletcher's cart) was provided to the students. It usually yields $g$ value with rather high accuracy and precision. The second method needed to be designed by the students. Most of the students' comments about this lab were very complimentary: "I like it $\mathrm{b} / \mathrm{c}$ we were pretty accurate in figuring $g<1 \%$ error. It was fun to design our own experiment. It had most room for creative-problem-solving." During the lab the students were excited to get a precise value of $g$. They were very enthusiastic to find their own method. They rejected the simplest but inaccurate methods to find better solutions even if though they were not required to do it by the write-up. Students designed interesting set-ups, and kept discussing the experiments after the class time. The survey comments and our direct observations indicated that many students were in the state of flow during this lab.

One of the least liked labs was "Collision" lab [10]:

"The collisions lab was the most stressful and confusing $b / c$ I did the whole lab using the wrong equation and wasn't told until the end. For a long time no one knew what to do." These comments indicate that the lab does not meet several flow conditions such as knowing what to do, how to do, and how well the person was doing. The perceived challenge was higher than the perceived skills' level bringing students to the anxiety mental state.

Flow at work: Changes for Spring 2013 Based on our observations and the survey's results we revised the structure of the course and changed each lab focusing on main aspects corresponding to the conditions of flow.

Lab reports: Students considered writing lab reports to be a boring activity with low challenge and they really had considerably high skill, so we decided to decrease the time that students spend on writing lab reports. We converted some labs to tutorials that did not require elaborate reports, thus decreasing number of formal lab reports from 9 to 5 .

Error analysis: Students showed lack of the important skill of evaluating uncertainties and dealing with systematic errors. They also expressed awareness of this lack in the skills and the understanding of their importance. To address this issue we added three special worksheet sessions for more detailed and rigorous learning of error analysis. The most liked lab: We analyzed the features of the most liked lab to see how it meets the flow conditions to make other labs as enjoyable as this one. These features are listed below: 
TABLE I. Analysis of students' difficulties in 2012 and the steps we took in 2013 in response. The right column shows the corresponding flow condition

\begin{tabular}{lll}
\hline \hline $\begin{array}{l}\text { Students struggled with new } \\
\text { concepts of collision. }\end{array}$ & $\begin{array}{l}\text { We moved the lab by two weeks so students felt much } \\
\text { more confident with conservation laws. }\end{array}$ & Knowing how to do \\
\hline $\begin{array}{l}\text { It was the first lab on collisions } \\
\text { and students felt unconfident } \\
\text { with the concepts }\end{array}$ & $\begin{array}{l}\text { The additional lab on perfectly inelastic collision gave a } \\
\text { good reliable outcome and helped students see that they } \\
\text { could perform well inventing concepts. }\end{array}$ & Increased perceived skills \\
\hline $\begin{array}{l}\text { Constructing mathematical } \\
\text { model appears to be unclear task } \\
\text { for students at this level. }\end{array}$ & $\begin{array}{l}\text { Measuring a value by two methods has clearer outcome: } \\
\text { If values are within uncertainty range, the experiment is } \\
\text { successful. }\end{array}$ & $\begin{array}{l}\text { Knowing how well you } \\
\text { are doing }\end{array}$ \\
\hline $\begin{array}{l}\text { Main focus of the lab was on the } \\
\text { collision part. The method for } \\
\text { determining the coefficient of } \\
\text { friction was given with video. }\end{array}$ & $\begin{array}{l}\text { The students had more time to design a second method } \\
\text { for determining the coefficient of friction. }\end{array}$ & $\begin{array}{l}\text { Increased opportunity for } \\
\text { equipment as pulley and weights . The foam board }\end{array}$ \\
& $\begin{array}{l}\text { allowed students to tilt the surface. } \\
\text { The challenge level of the } \\
\text { task corresponds to } \\
\text { students' skill level }\end{array}$ \\
\hline \hline
\end{tabular}

a) Clear objectives, so students knew what to do;

b) By the time of the lab students were familiar with measurement techniques and equipment, so they knew how to do it;

c) Clear outcome. Students were able to evaluate the results and decide whether the values were within the uncertainty range, and whether the experiment was successful. Students knew how well they were doing; d) The given method yields a good reliable outcome. The students see that they can perform well. That increased the perceived level of skills.

e) Weaker students came with simple imprecise methods; more advanced students designed relatively sophisticated experiment focusing on minimizing uncertainties. The challenge level corresponds to students' skill level.

The least liked lab: We analyzed other labs to find tasks that mismatched the flow conditions. Table I shows this analysis of one of such labs "Collision" along with our steps to make it match the flow conditions. We moved the whole lab after a week of studying collisions and after another lab "Ballistic pendulum" related to a totally inelastic collision. We rephrased the objectives so instead of building a model, students determined the coefficient of kinetic friction between the box and the foam board by two methods. We supplied more available equipment such as pulleys, set of objects of different masses, force sensors and others. We decreased scaffolding that prompted students to use a certain method for measuring the coefficient of friction. As a result the students could come up with original ideas.

\section{FINDINGS AND DISCUSSION}

The survey showed that the overall attitude towards the labs had improved significantly. In this paper we focus on two specific questions.

The responses "To what extent were these labs fun and interesting?" indicate general students' attitude towards the labs. In year 2012, the average score was slightly negative $(3.8, \sigma=1)$, while in year 2013 it was strongly positive $(5.4, \sigma=1)$.

The second question "To what extent was the instructor's help needed?" indicated how the students perceived the tasks relative to their skills level. The higher numbers (5-7) show that the task was difficult enough for the student to seek help. Lower numbers (1-3) represent a lower challenge relative to the student skill level. In 2012, the average score shows that labs were rather difficult $(5.6, \sigma=1)$, while in 2013 the score was neutral $(4.0, \sigma=2)$.

Further analysis of answers to these two questions gave us an indication of how close the student was to state of flow, or apathy, or other states. On the chart "difficulty" vs. "fun" the answers to these two questions (figure 2) can be grouped according to four quadrants. One quadrant describes the labs that were considered to be easy and not interesting, in other words students were in states of boredom and apathy. Other quadrants are for difficult and not interesting labs (anxiety and worry); for difficult and fun (arousal and flow); and for easy and fun (control and relaxation).

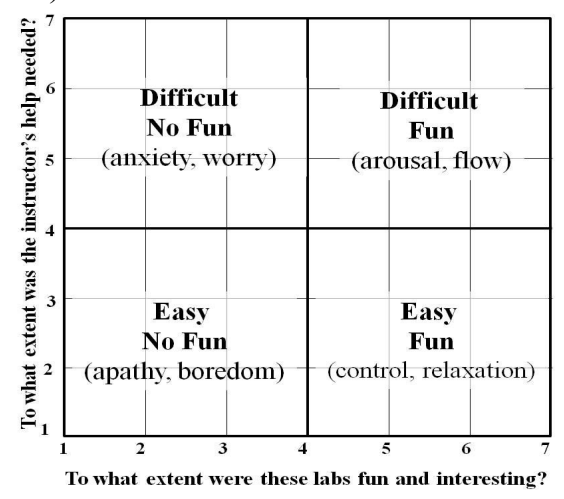

FIG.2. Diagram of students' answers to questions "To what extent was the instructor's help needed?" and "To what extent were these labs fun and interesting?" in terms of the eight-channel model. 

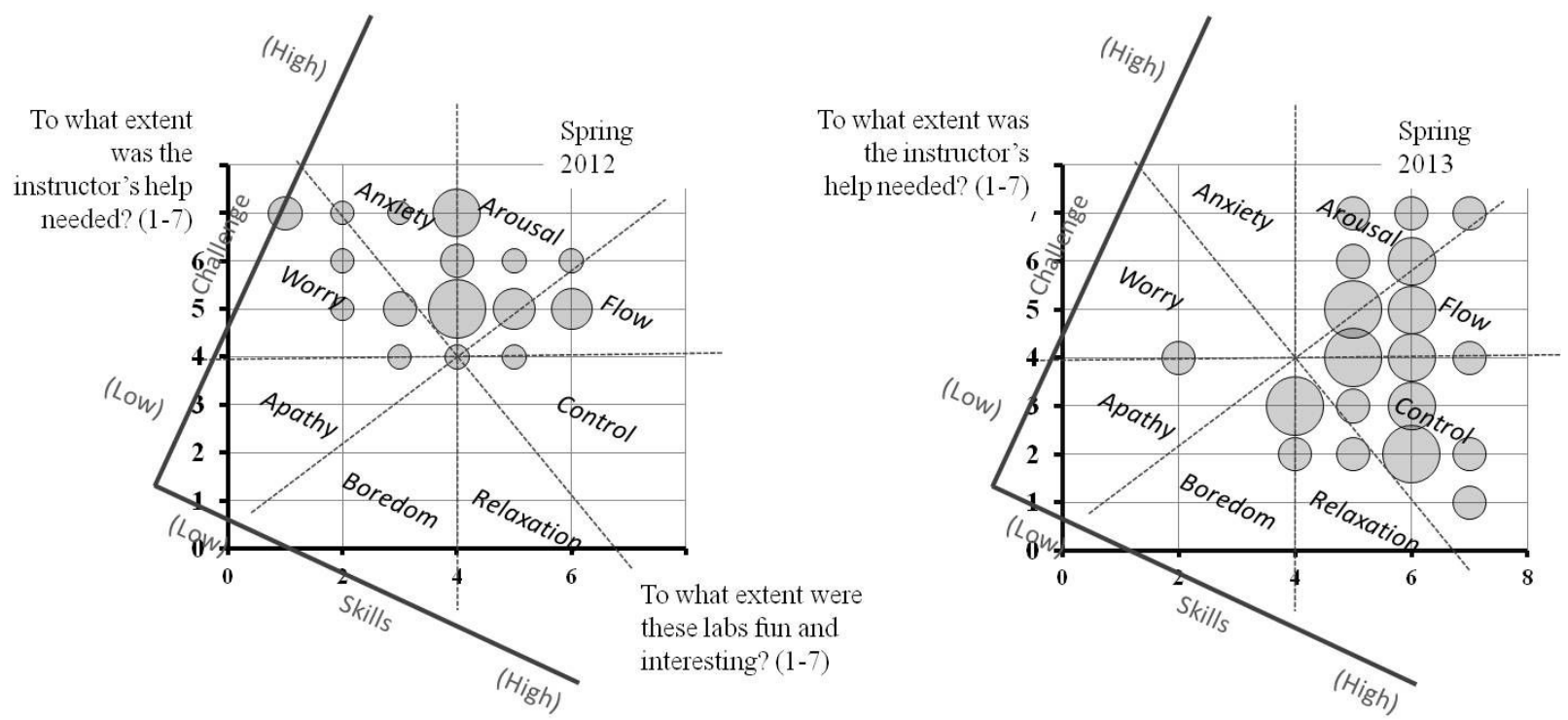

FIG.3. Students' responses with a mental state diagram. Results of Spring 2012 and 2013.

This representation allows us to have a rough qualitative interpretation of students' responses these two questions through the lens of the flow theory. We can represent students' responses on this chart "difficulty" vs. "fun" with bubble sizes proportional to the number of students. The position of each bubble on this graph corresponds to the mental state of the student as shown in Figure 3. The results show that in year 2012 most of the students were in states "worry", "anxiety" and "arousal". In year 2013 we can see that most of the students were in states "arousal", "flow", and "control" with few students in "relaxation" state.

\section{IMPLICATIONS}

Based on our findings we can formulate suggestions

[1] E. Etkina, Am. J. Phys., 83, 669 (2015)

[2] E. Etkina and M. Ruibal-Villasensor, AIP Conf. Proc., 883, 105-108 (2007).

[3] M. J. Volkmann, S. K. Abell, and M. Zgagacz, Science Education, 89, 847, (2005).

[4] M. Csikszentmihalyi, Flow: The Psychology of Optimal Experience, (Harper and Row, New York, NY, 1990).

[5] J. Nakamura, J. and M. Csikszentmihalyi, in Handbook of positive psychology, edited by C. R. Snyder and S. J. Lopez, (Oxford University Press, Oxford, UK, 2002), pp. 89-105.

[6] F. Massimini and M. Carli in Optimal Experience: Psychological Studies of Flow in Consciousness, edited by M. Csikszentmihalyi, for those who want to implement the labs where students design their own experiments:

a) The labs' objectives should be very clear to students so they know what to do;

b) Tasks should be attainable to students with minimal help from an instructor;

c) Tasks should have a clear outcome indicating a success for a clear feedback;

d) Available equipment should give a large range of possible ways to solve a problem to increase perceived challenges;

e) Exercises can be added to increase specific skills when students are aware of their luck of the skills; in Ref. 11 we found that student need about 5-8 weeks to develop different abilities, thus that the difficulty of the tasks should increase during the semester.

and I. Csikszentmihalyi (Cambridge University Press, 1988), pp. 266-287.

[7] G. B. Moneta, in Advances in Flow Research, edited by Stefan Engeser (New York, NY: Springer, 2012), pp. 23-50.

[8] E. Etkina, S. Murthy, and X. Zou, Am. J. Phys. 74, 979 (2006).

[9] A. Karelina, AAPT conference, Orlando, FL, 2014.

[10] The texts of the labs can be found on site https://sites.google.com/site/scientificabilities/IS LE-labs; "Calculus based", Semester 2, Mechanics

[11]A. Karelina and E. Etkina, Phys. Rev. ST Phys. Educ. Res., 3, 020106 (2007). 